\title{
Rituximab, MS, and pregnancy
}

Jessica B. Smith, MPH, Kerstin Hellwig, MD, Katharina Fink, MD, PhD, Deirdre J. Lyell, MD, Fredrik Piehl, MD, PhD, and Annette Langer-Gould, MD, PhD

Neurol Neuroimmunol Neuroinflamm 2020;7:e734. doi:10.1212/NXI.0000000000000734

\section{Abstract}

\section{Objective}

To describe the safety and efficacy of rituximab (RTX) in MS and pregnancy, we conducted a retrospective cohort study of 74 pregnancies among 55 women treated with RTX for MS and their offspring.

\section{Methods}

We used prospectively collected information from the electronic health record at Kaiser Permanente Southern California between 2012 and 2019 of mother and baby to identify treatment history, pregnancy outcomes, and relapses.

\section{Results}

Last RTX exposure before conception occurred between 1.8 and 5.2 months in 32 (49\%) of 65 pregnancies and accidentally during the first trimester in 9 (12\%). Among 38 live births, adverse pregnancy outcomes were as follows: 3 preterm deliveries (including 1 set of twins), 1 neonatal death (preterm twin), and 1 perinatal stroke (full-term). No stillbirths, chorioamnionitis, or major malformations were found. Fifteen (27\%) women had at least one first-trimester miscarriage, of whom 8 (53\%) had a history of infertility. Cumulative dose or timing of last RTX infusion was not associated with an increased risk of miscarriage. Only 2 (5.4\%) women experienced relapses, one during pregnancy and the other postpartum.

\section{Conclusion}

We observed no increase in adverse pregnancy outcomes compared with expected national incidence rates and remarkably little disease activity in RTX-treated women with MS, particularly when compared with periconceptional natalizumab-treated cohorts. However, larger studies are needed to fully assess the safety of RTX use before pregnancy, especially risks associated with prolonged B-cell depletion and hypogammaglobulinemia. Until these data are available, we recommend restricting RTX use before pregnancy to women who require highly effective MS treatments.

\section{Classification of evidence}

This study provides Class IV evidence that for pregnant women with MS, RTX controls disease activity and does not increase adverse pregnancy outcomes.
Correspondence

Dr. Langer-Gould

Annette.M.Langer-Gould@kp.org

\section{$\rightarrow$ Class of Evidence}

Criteria for rating

therapeutic and diagnostic

studies

NPub.org/coe 


\section{Glossary}

BMI = body mass index; CIS = clinically isolated syndrome; DMT = disease-modifying treatment; EDD = expected delivery date; EHR = electronic health record; gw = gestational week; $\mathbf{I Q R}=$ interquartile range; KPSC = Kaiser Permanente Southern California; LMP = last menstrual period; RA = rheumatoid arthritis; $\mathbf{R C T}=$ randomized controlled trial; RIS = radiologically isolated syndrome; $\mathbf{R T X}=$ rituximab.

We recently found that $67 \%$ of women with MS entered pregnancy with suboptimally controlled disease in our large, population-based cohort. ${ }^{1}$ These findings led to the development of a pregnancy-specific MS treatment algorithm in KPSC $^{2}$ that prioritizes the use of rituximab (RTX) in these women over fingolimod, natalizumab, or other highly effective disease-modifying treatments (DMTs).

RTX is an attractive treatment option in women with MS who desire pregnancy and require a highly effective DMT because its immunomodulatory effects last long after the drug has been eliminated, ${ }^{3}$ and RTX is not associated with drug-cessation relapses. ${ }^{4-6}$ We recommend starting RTX before pregnancy, typically $500 \mathrm{mg}$ every 6 months, holding infusions during pregnancy and resuming infusions typically 6-12 months postpartum or sooner if disease activity returns or is desired by the mother.

We based these recommendations mainly on the high risks of using other highly effective DMTs and the low biological plausibility of harm with relatively low doses of RTX before pregnancy. ${ }^{7}$ However, data regarding safety and efficacy of RTX in human pregnancies are scant, particularly in MS. No studies were adequately designed to assess the effect of RTX on miscarriages or stillbirths. This is important because a plausible risk of prolonged B-cell depletion from high-dose RTX or other B-cell depleting agents could increase the risk of systemic maternal infections or chorioamnionitis, leading to miscarriages, preterm birth, or stillbirths. It is concerning that the drug company's global safety database reported a high number of preterm births ${ }^{8}$; however, these data are difficult to interpret because they combined outcomes from women with a wide variety of underlying diseases, some of which were predisposed to poor pregnancy outcomes, received RTX during late pregnancy, and/or were coadministered teratogenic medications. Other significant methodological limitations precluding clear interpretation of the manufacturer's study ${ }^{8}$ and a subsequent systematic review ${ }^{9}$ include reporting bias, selection bias, missing data, and reliance on case reports.

The objective of this study was to assess the risk of miscarriages, adverse pregnancy and neonatal outcomes, and maternal disease control in a well-defined cohort of women with MS treated with RTX.

\section{Methods}

\section{Study population}

Pregnant women with MS were identified through the membership of Kaiser Permanente Southern California (KPSC). We searched electronic databases to identify members who received RTX infusions for MS or its potential precursors, clinically isolated syndrome (CIS) or radiologically isolated syndrome (RIS), between January 2012 and November 2019. We used a combination of International Classification of Diseases, 9th and 10th Revisions codes for MS, optic neuritis, and transverse myelitis and pregnancy ${ }^{10}$ to identify potentially eligible subjects. The complete electronic health records (EHRs) were then reviewed to determine eligibility by an MS expert (A.L.-G.). All KPSC members who met the $2017 \mathrm{McD}$ onald criteria for MS, ${ }^{11} \mathrm{CIS},{ }^{12}$ or RIS ${ }^{13}$ at the onset of pregnancy and had received at least 1 RTX infusion before conception or within 2 months of last menstrual period (LMP) were included. Women who had no history of RTX infusions before or around the time of conception or had conditions other than MS, CIS, or RIS were excluded.

KPSC is a large prepaid healthcare organization that provides comprehensive health care, including inpatient, outpatient, pharmacy, laboratory, and radiology services to over 4 million members in Southern California. The membership of KPSC is representative of the general Southern California population. ${ }^{14}$ KPSC uses an integrated EHR system that includes all inpatient and outpatient encounters, diagnostic tests, diagnoses and medications, and some demographic and behavioral characteristics.

\section{Standard protocol approvals, registrations, and patient consents}

The study protocol was approved by the KPSC institutional review board.

\section{Data collection}

Symptom onset, relapses, MRI disease activity, and disability level were abstracted from the mother's EHR by an MS expert (A.L.-G.). Relapses were defined as the occurrence, reappearance, or worsening of symptoms of neurologic dysfunction lasting for 48 hours or more and needed to be documented by a treating physician during a physical examination. Symptoms that occurred within 1 month of each other were part of the same relapse. MRIs were obtained as part of routine clinical care. MRI disease activity was defined as an unequivocally new or enlarging T2 lesion, new diffusion-restricting or gadoliniumpositive lesion(s). Comparisons were made with previous 
MRIs. Radiology reports were reviewed by a research professional (J.S.), and hard copies were reviewed by an MS specialist (A.L.-G.). Twenty of 34 (58.8\%) postpartum MRIs were performed with and without contrast. Treatment history was collected through electronic searches and verified via EHR review conducted by a research professional (J.B.S.).

Risk factors for adverse pregnancy outcomes (infertility, comorbidities, body mass index (BMI) at conception $\geq 25,{ }^{15}$ smoking, black race, substance use, thrombophilia, thyroid disease, and infection), LMP, expected delivery date (EDD), gravidity, parity and pregnancy, and labor and delivery outcomes were abstracted from maternal EHRs by a research professional (J.B.S.). Neonatal outcomes, breastfeeding, formula feeding, and introduction of solid food were abstracted from the infant's medical record as previously described. $^{1}$

\section{Statistical analyses}

The primary purpose of analyses was to describe adverse pregnancy outcomes and maternal disease control in women with MS being treated with RTX. To allow for comparison with the national and California (whenever available) rates, we used the Centers for Disease Control definitions for low birthweight (less than 2,500 g), ${ }^{16}$ very low birthweight (less than $1,500 \mathrm{~g}),{ }^{16}$ small for gestational age (SGA, birthweight at or below the 10th percentile for a given gestational age), ${ }^{17}$ stillbirth (death or loss of baby after 20 weeks completed pregnancy weeks), ${ }^{18}$ preterm delivery (less than 37 weeks gestational age), ${ }^{19}$ and major malformations. We were also interested in chorioamnionitis or systemic maternal infections that could potentially lead to adverse pregnancy outcomes given the mechanism of action of RTX. Therefore, we describe RTX dosing before or during each pregnancy.

When examining the risk factors for adverse pregnancy outcomes, we describe the maternal characteristics at first pregnancy during the study period to account for women with multiple pregnancies.

Pregnancies ending in the first-trimester miscarriages were excluded from the maternal disease course outcomes to allow for comparison with other populations. ${ }^{1,20}$ For graphical depiction purposes, we divided the prepartum and postpartum years into 3-month intervals.

To examine the potential impact of resuming RTX on breastfeeding choices, we used previously published definitions. ${ }^{1,21}$ Breastfeeding was defined as exclusive (no regular formula feeding for at least the first 2 months postpartum), nonexclusive (breastfeeding and regular formula feeding within 2 months), or none.

The baby of one woman who delivered outside of KPSC, but whose postpartum neurology notes and date of delivery were available, was excluded from descriptions of birthweight, major malformations, and breastfeeding because we were not able to access the infant records.

Women or pregnancies that were not eligible for the outcome described were excluded from the denominator when calculating percentages. For instance, first-trimester miscarriages, elective abortions, and ongoing pregnancies were excluded when describing infant outcomes.

The means and SDs of normally distributed variables were compared using 2 sample $t$ tests; for variables with nonnormal distributions, the Wilcoxon rank-sum test was used; and for binary or categorical variables, $\chi^{2}$ with the Fisher exact test was used to compare periconceptional RTX exposure characteristics in pregnancies ending or not ending in miscarriages and clinical characteristics of the mothers with or without at least one post-RTX exposure miscarriage. Statistical significance was set a priori at $p=0.20$ to detect potential confounders, given the small sample and purpose of analyses to detect any signal of adverse pregnancy outcomes. ${ }^{22}$ No adjustment for multiple comparisons was made. All statistical analyses were performed using SAS version 9.4 (SAS Institute Inc, Cary, NC).

\section{Data availability}

Owing to KPSC's institutional review board, data would be available upon reasonable request.

\section{Results}

\section{Disease characteristics, risk factors for adverse pregnancy outcomes, and periconceptional RTX exposure}

We identified 55 women with MS who conceived 74 pregnancies after exposure to at least one dose of RTX during the study period. Seventeen women had 2 pregnancies, and one had 3 pregnancies. General characteristics of the women with MS at the onset of their first RTX-exposed pregnancy are presented in table 1 . Many women with MS $(n=40)$ had previously been treated with other DMTs, of whom 16 (29.1\%) were clinically and radiographically stable on their previous DMT and switched to RTX solely for pregnancy planning. Thirty-four (62\%) women were nulliparous. Sixteen women $(29 \%)$ had been diagnosed with infertility, 5 from polycystic ovarian syndrome, 2 from structural causes, and 1 each from premature ovarian failure, age-related infertility, and factor V Leiden deficiency. In 6 women, the cause of infertility was unknown.

Forty-six (84\%) women had at least one risk factor for adverse pregnancy outcomes, including miscarriages before starting RTX $(\mathrm{n}=11,20 \%)$, overweight (BMI $\geq 25$, $\mathrm{n}=33,60 \%)$, age $\geq 35$ at $\operatorname{EDD}(\mathrm{n}=15,27 \%)$, being black $(n=10)$, gestational diabetes $(n=5)$, thyroid dysfunction $(n=2)$, and 1 each of the following: diabetes before pregnancy, smoking during pregnancy, twin pregnancy, or retained intrauterine device. 
Table 1 Characteristics of women with MS at the onset of first RTX-exposed pregnancy

\begin{tabular}{ll}
\hline & $\mathbf{n}=\mathbf{5 5}$ \\
\hline Age, median (IQR), $\mathbf{y}$ & $31.1(28.0-34.5)$ \\
\hline Race/ethnicity, $\mathbf{n}(\%)$ & $15(27.3)$ \\
\hline White & \\
\hline Hispanic & $21(38.2)$ \\
\hline Black & $22(40.0)$ \\
\hline Asian & $10(18.2)$ \\
\hline
\end{tabular}

Obesity, $\mathbf{n}(\%)$

BMI at conception, median (IQR)

$26.6(22.9-30.5)$

\begin{tabular}{ll}
\hline Normal weight $(<\mathbf{2 5})$ & $22(40.0)$ \\
\hline Overweight $(\geq \mathbf{2 5}$ to $<30)$ & $18(32.7)$ \\
\hline Obese Class I $(\geq \mathbf{3 0}$ to $<35)$ & $9(16.4)$ \\
\hline Obese Class II $(\geq \mathbf{3 5}$ to $<\mathbf{4 0})$ & $2(3.6)$ \\
\hline Obese Class III ( $\geq \mathbf{4 0})$ & $4(7.3)$ \\
\hline Infertility, $\mathbf{n}(\%)$ & $16(29.1)$ \\
\hline Previous miscarriages, $\mathbf{n}(\%)$ & $11(20.0)$
\end{tabular}

Gravidity, n (\%)

\begin{tabular}{lc}
\hline $\mathbf{1}$ & $26(47.3)$ \\
\hline $\mathbf{2}$ & $16(29.1)$ \\
\hline $\mathbf{3 +}$ & $13(23.6)$
\end{tabular}

\section{Parity, n (\%)}

\begin{tabular}{ll}
\hline $\mathbf{0}$ & $34(61.8)$ \\
\hline $\mathbf{1}$ & $14(25.5)$ \\
\hline $\mathbf{2 +}$ & $7(12.7)$ \\
\hline MS subtype, $\mathbf{n}$ (\%) & $54(98.2)$ \\
\hline RRMS & $1(1.8)$ \\
\hline RIS & $5.3(2.6-8.7)$ \\
\hline Disease duration, median (IQR), $\mathbf{y}$ & $28(50.9)$ \\
\hline No. of relapses 2 year prepregnancy, $\mathbf{n}(\%)$ & $16(29.1)$ \\
\hline $\mathbf{0}$ & $11(20.0)$ \\
\hline $\mathbf{1}$ & $2.0(1.0-3.0)$ \\
\hline$\geq 2$ & \\
\hline EDSS, median (IQR) & $15(27.3)$ \\
\hline DMT use before RTX, $\mathbf{n}(\%)$ & $4(7.3)$ \\
\hline None & $14(25.5)$ \\
\hline Fingolimod & \\
\hline Natalizumab & \\
\hline
\end{tabular}

Table 1 Characteristics of women with MS at the onset of first RTX-exposed pregnancy (continued)

\begin{tabular}{ll}
\hline & $\mathbf{n}=\mathbf{5 5}$ \\
\hline IFN-betas & $10(18.2)$ \\
\hline Glatiramer acetate & $8(14.5)$ \\
\hline Other $^{\mathbf{a}}$ & $4(7.3)$ \\
\hline
\end{tabular}

Abbreviations: $\mathrm{BMI}=$ body mass index; $\mathrm{DMT}$ = disease- modifying treatment; EDSS = expanded disability status scale; IQR = interquartile range; IFN = interferon, RIS = radiologically isolated syndrome; RRMS = relapsing-remitting MS; RTX = rituximab.

${ }^{a} n=2$ dimethyl fumarate, $n=1$ cyclophosphamide and $n=1$ azathioprine.

Most pregnancies $(\mathrm{n}=59,80 \%)$ were conceived within 6 months after the last RTX infusion, including 9 pregnancies with accidental 1st trimester exposure (table 2). Only 6 pregnancies occurred more than 12 months after the last dose, including a woman with RIS who received one infusion with plans for further treatment only on return of disease activity. RTX exposure during pregnancy was uncommon, occurring accidentally in $9(12 \%)$ pregnancies during the first trimester with a median time from LMP of 2 weeks, ranging from 0.5 to 5 weeks after LMP. No pregnancies were exposed to RTX infusions during the second or third trimester. Half of the pregnancies were conceived after 3 or more RTX infusions, with a median cumulative dose of 2,000 $\mathrm{mg}$ (table 2).

\section{Pregnancy, labor, delivery, and neonatal outcomes}

Pregnancy outcomes after at least 1 dose of RTX are shown in figure 1. Fifteen (27\%) women had 23 first-trimester miscarriages; 6 women had 2 and 1 had 3 . No miscarriages after 12 weeks or stillbirths occurred. A diagnosis of infertility was the only adverse pregnancy risk factor measured that differed significantly between women who had pregnancies ending in miscarriages $(53 \%, \mathrm{n}=8)$ compared with those who did not $(20 \%, \mathrm{n}=8 ; p=0.0223)$. Cumulative RTX dose, duration of RTX, the number of infusions, accidental 1st trimester exposure, and timing of the last infusion before pregnancy were all similar $(p>0.20)$ among pregnancies ending in miscarriages compared with those ending in full-term or preterm births or elective abortions (appendix e-1, links.lww.com/ NXI/A246). Five (33\%) of the 15 women with miscarriages had successful pregnancies on RTX, and another 2 (13\%) women are currently in the third trimester. None of the women discontinued RTX because of miscarriages or other adverse pregnancy outcomes.

Of the 45 pregnancies that advanced past the first trimester, 37 resulted in 38 live births and 8 are ongoing ( 3 in the 2 nd trimester and 5 in the 3 rd trimester; figure 1 ). Most of the live births were normal, full-term babies $(n=33,89 \%)$. The average birthweight among full-term neonates was $3,217.2 \mathrm{~g}$ (SD 346.3). None of the pregnancies were complicated by chorioamnionitis. 
Table 2 Periconceptional RTX exposure at the onset of each pregnancy

\begin{tabular}{|c|c|}
\hline & $\mathrm{n}=74$ pregnancies \\
\hline \multicolumn{2}{|l|}{ Most recent RTX infusion } \\
\hline During pregnancy, $n$ (\%) & $9(12.2)$ \\
\hline Accidental 1st trimester exposure, $n(\%)$ & $9(100)$ \\
\hline Median (IQR) from LMP, mo & $0.5(0.3-0.7)$ \\
\hline Before conception, $\mathbf{n}(\%)$ & $65(87.8)$ \\
\hline Median (IQR), mo & $3.4(1.8-5.2)$ \\
\hline 0-6 mo, n (\%) & 50 (76.9) \\
\hline$>6$ mo, n (\%) & $15(23.1)$ \\
\hline Duration of use, median (IQR), mo & $12.4(4.4-25.3)$ \\
\hline Cumulative dose, mg, median (IQR) & $2000(1,000-3,000)$ \\
\hline Cumulative no. infusions, median (IQR) & $3.0(2.0-4.0)$ \\
\hline
\end{tabular}

Abbreviations: IQR = interquartile range; LMP = last menstrual period; no. = number; RTX = rituximab.

Three pregnancies $(8.1 \%)$ ended in preterm deliveries of 4 babies, including one set of 27-gestational-week (gw) twins. The other preterm infants were noted as a normal spontaneous vaginal delivery (36 gw) or premature rupture of membranes from incompetent cervix (34 gw).

The 27-week twins were both $<1,500 \mathrm{~g}$, and 1 twin died 6 days after delivery from an intraventricular hemorrhage. Another preterm baby weighed $<2,500 \mathrm{~g}$, but no babies were SGA. In addition to these 3 preterm, low birthweight babies, another baby was admitted to the neonatal intensive care unit for perinatal ischemic stroke and seizures after vacuum-assisted delivery for prolonged labor and fetal distress after a 40-week pregnancy complicated only by mild pre-eclampsia. Extensive workup to identify a cerebrovascular, cardiac, or genetic etiology of perinatal stroke was negative.

The last RTX dose before pregnancy was 2.3 months for the mother of the twins, 9.5 months for the mother of the neonate with stroke and seizures, and 2 days after LMP for the mother of the $34 \mathrm{gw}$ preterm baby. The mother with twins had a history of infertility from premature ovarian failure and had failed multiple rounds of in vitro fertilization before starting RTX.

Caesarean sections were performed in 13 (35\%) pregnancies, of which 6 were emergencies. The remaining 24 (65\%) pregnancies ended with vaginal deliveries.

\section{Maternal disease course, pregnancy, breastfeeding, and postpartum RTX use}

Very few relapses or MRI disease activity occurred after the first dose of rituximab prepartum, intrapartum, or during the postpartum period in women with live births (figure 2). Only
$1(2.7 \%)$ relapse occurred during pregnancy with the most recent RTX dose 3 months before conception and 1 (2.7\%) during the 12-month postpartum where the most recent RTX dose was 4 months before conception. These 2 women with relapses resumed RTX postpartum after their relapses. No postpartum MRI disease activity was detected among the 22 (59\%) women who had an MRI in the postpartum year.

RTX was resumed after 24 (65\%) pregnancies ending in live births within 12 months postpartum (figure 2). RTX was not resumed after 9 pregnancies (24\%) within 12 months postpartum, none of whom had a relapse or active MRI, and 4 have not resumed RTX but are not yet 1 full year postpartum. Among those resuming RTX in the postpartum year, the median time to restarting was 2.2 months (interquartile range [IQR $]$ 1.0-5.7) postpartum and the median interval from last RTX dose to first postpartum dose was 14.6 months (IQR 11.3-18.4).

Most babies were breastfed $(89 \%, n=34)$, of which $13(35 \%)$ were breastfed exclusively for at least 2 months or more. Eight (22\%) babies were still being breastfed when their mothers resumed RTX infusions.

No postpartum relapses occurred after the 23 first-trimester miscarriages during a median follow-up time of 12 months (IQR 4-12). RTX was resumed during this timeframe after 13 (56.5\%) miscarriages.

\section{Discussion}

Our findings show that using RTX 500 mg every 6-12 months before pregnancy and simply holding infusions during pregnancy results in remarkably well-controlled MS disease activity without a signal for increased risk of harm to the baby. RTX was used primarily in women with suboptimally controlled MS or in those controlled on fingolimod or natalizumab who desired pregnancy, consistent with the KPSC algorithm. The findings are reassuring for these women who are at high risk of pregnancy-related relapses and/or longterm MS-related disability but are insufficient to recommend expanding routine RTX use to women at low risk of long-term disability or pregnancy-related relapses. Specifically, the women in this study received relatively few and low doses of RTX; thus, potential risks of longer term, higher dose use of RTX on adverse pregnancy outcomes, particularly maternal or neonatal infections, remain unknown. Our findings should also not be extrapolated to other B-cell depleting treatments, where the risk of hypogammaglobulinemia appears to be significantly higher and occurs earlier ${ }^{23}$ than with the doses of RTX used in this study. ${ }^{24}$

The KPSC MS and Pregnancy Treatment algorithm was developed because, in 2017, we found that $67 \%$ of women in KPSC and KP Northern California had suboptimally controlled disease entering pregnancy, yet very few had been treated with 


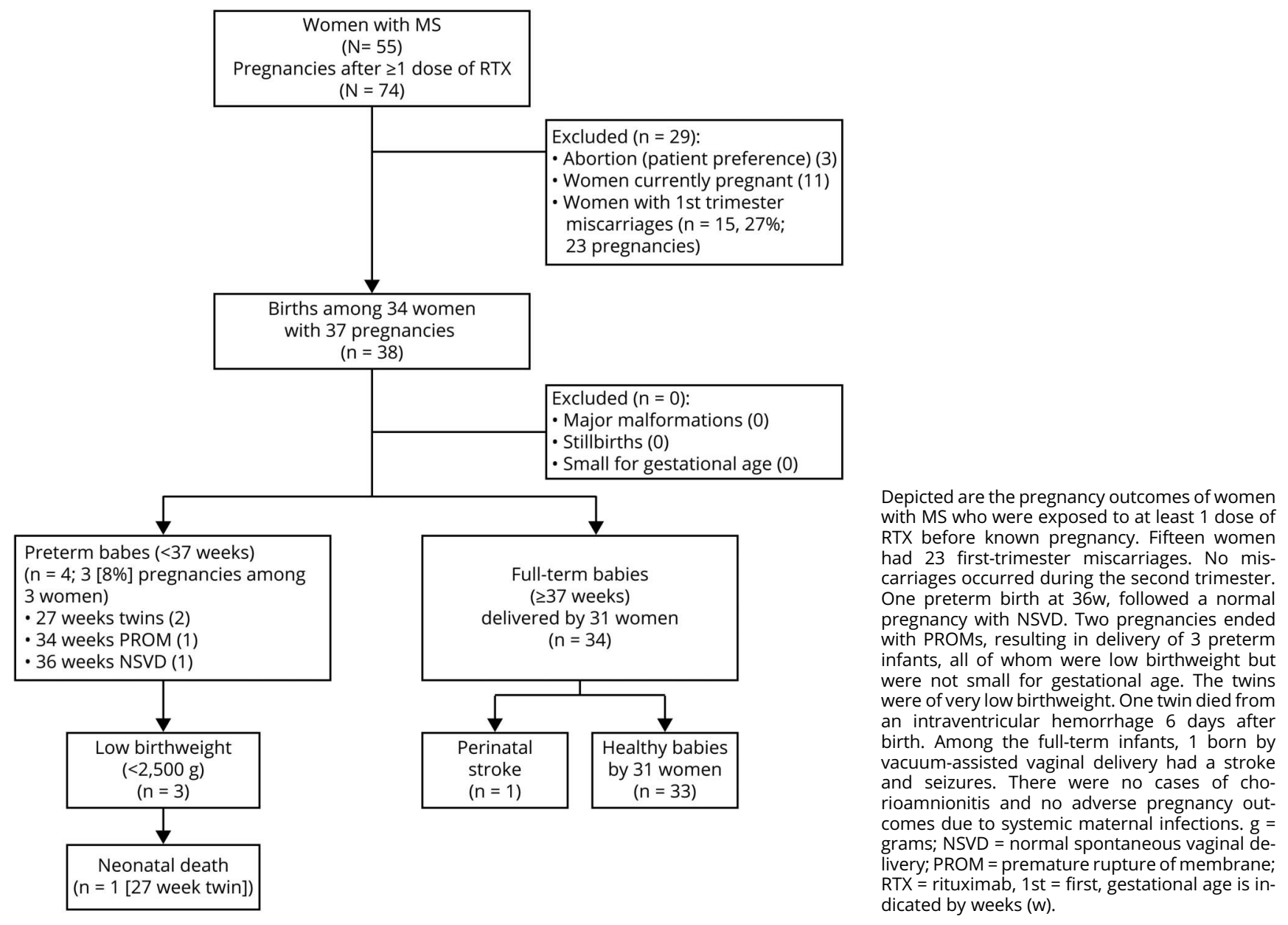

highly effective DMTs. ${ }^{1}$ Optimizing disease control before pregnancy is important because MS-related disability is a predictor of poor long-term prognosis ${ }^{25}$ and an independent predictor of postpartum relapses, along with the prepregnancy relapse rate and relapses during pregnancy. ${ }^{1,20,26-28}$ We prioritize RTX use in these women because the other commonly used, highly effective DMTs, natalizumab and fingolimod, are associated with an increased risk of rebound disease activity. $^{7,29,30}$ These rebound relapses can be severe ${ }^{29}$ and, if they occur during pregnancy, necessitate treatments that carry some risk of adverse pregnancy and neonatal outcomes, including repeated courses of glucocorticoids, resuming natalizumab, or starting RTX during late pregnancy. In addition, fingolimod is a weak teratogen with a long half-life; thus, discontinuing before conception is imperative. Although we and others have continued natalizumab throughout pregnancy when the risk of a severe MS-rebound relapse was judged to be high, this is not an optimal approach because natalizumab use during the third trimester can result in neonatal cytopenia with uncertain risks, including intraventricular hemorrhages. ${ }^{29}$ Therefore, we reasoned that it is more prudent to switch women who desire pregnancy from fingolimod or natalizumab to RTX before conception.
In this study, we show that periconceptional use of RTX resulted in significantly fewer relapses during pregnancy and the postpartum period compared with our previously published contemporary cohort ${ }^{1}$ ( $2.7 \%$ vs $8.6 \%$ during pregnancy and $2.7 \%$ vs $26.4 \%$ postpartum, respectively). This remarkably well-controlled disease activity starkly contrasts with the relatively high risk of pregnancy-related relapses with periconceptional natalizumab use, where $36.5 \%$ relapsed during pregnancy and $22 \%$ relapsed in the first 3 months postpartum alone. $^{31}$

We strongly encourage women to breastfeed exclusively, given the plethora of maternal and infant health benefits. ${ }^{32}$ Although exclusive breastfeeding appears to reduce the risk postpartum MS relapses, ${ }^{1}$ the rates of exclusive breastfeeding were similar in this cohort compared with our previous study ${ }^{1}$; thus, an unlikely explanation for the disease protection afforded by RTX.

We consider RTX to be compatible with breastfeeding and recommend restarting infusions 6-12 months postpartum or sooner if disease activity returns. ${ }^{2}$ However, in this cohort, half the women restarted RTX within 6 months postpartum 
Figure 2 Periconceptual and postpartum RTX infusions and MS relapses after the initiation of RTX among pregnancies ending in live births

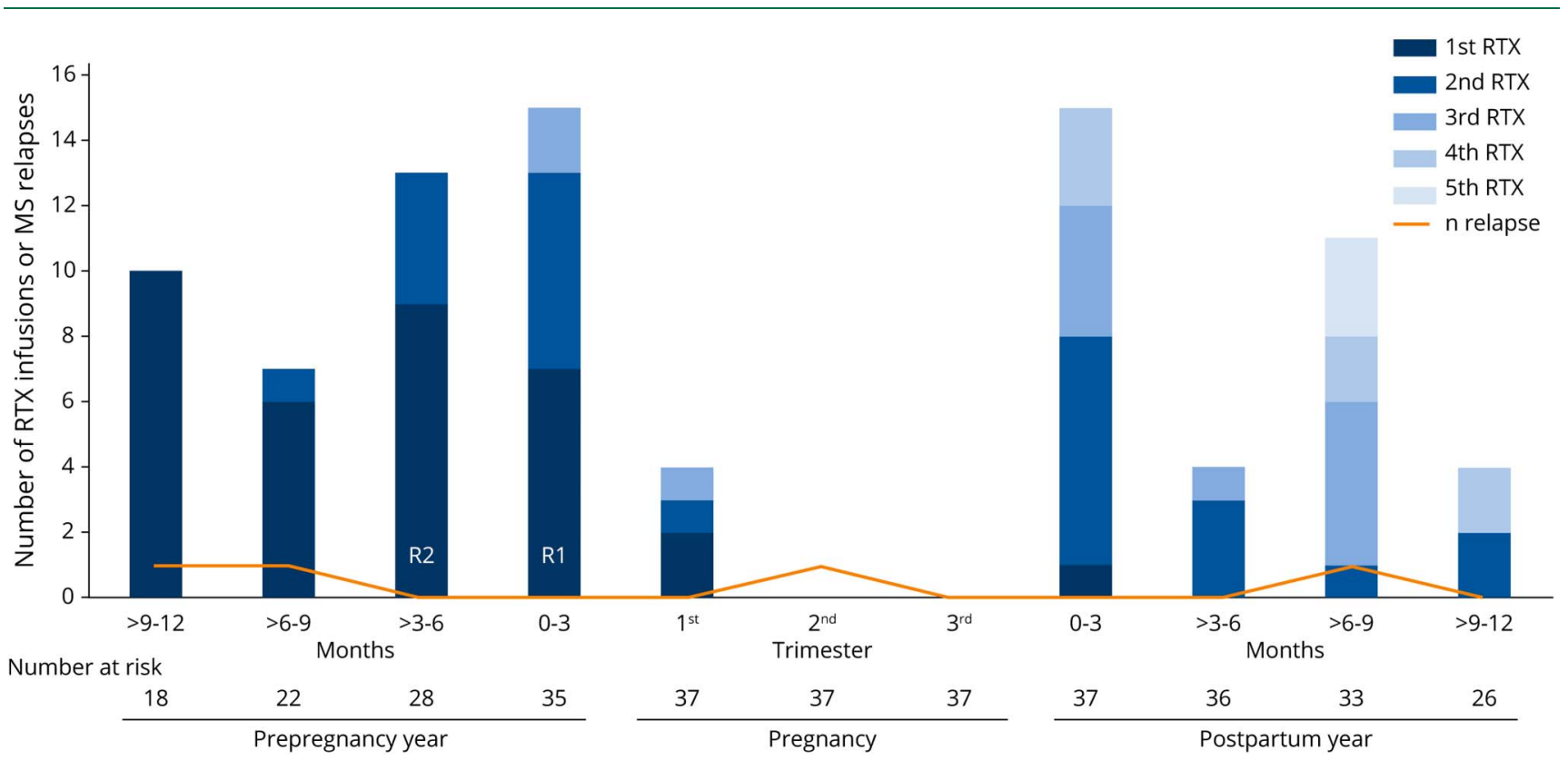

Depicted are the number of RTX infusions (blue bars) and MS relapses (orange line) that occurred during the study period among pregnancies ending in live births ( $n=37$ ) who received at least 1 RTX infusion before conception or during the first trimester (Tri). The study period encompasses the 12 months before conception, pregnancy, and the 12 months postpartum divided into 3-month intervals. Four women relapsed during the study period after initiating RTX. Only 2 women relapsed during pregnancy or the postpartum period, 1 during the 2 nd trimester of pregnancy who received her most recent RTX infusion 3 months before conception (R1), and one between 6 and 9 months postpartum who received her most recent RTX infusion 3.9 months before conception (R2). Two additional women had relapses after RTX initiation in the 12 months before conception; 1 woman 10.3 months before conception who received her most recent RTX infusion 4.5 months before relapse, and another woman who relapsed 8.5 months before conception, 0.9 months after her first RTX infusion. Most pregnancies $(n=25,68 \%)$ occurred within 6 months of their most recent RTX infusion. Increasing numbers of RTX infusions over the study period are denoted by increasingly lighter shades of blue. The darkest blue shading indicates the first RTX infusion during the study period of which most ( $\mathrm{n}=32$ ) occurred during the 12 months before conception. The woman who is depicted with her first RTX infusion occurring 0-3 months postpartum had her last RTX infusion more than 12 months before conception. Two additional women received their last RTX infusion >12 months before conception; neither had resumed RTX before the end of the study period. Twenty-one women received their first ever infusion of RTX in the year before pregnancy and 2 shortly after their last menstrual period. Twelve women received 2 infusions, 6 received 3 infusions, 4 had 4 infusions, and 3 had 5 RTX infusions (lightest shade of blue) during the study period. The number of women at risk are those who had received at least 1 infusion of RTX before pregnancy (or shortly after conception). In the postpartum period, the number of women at risk also incorporates the duration of the follow-up. No women have been lost to follow-up, but 11 women are less than 12 months postpartum. RTX = rituximab.

although only one had signs of the return of disease activity. Similarly, this was because of a cautionary approach among clinicians and/or patients regarding the risks of being untreated. To what extent resuming RTX influenced the quiescence of disease activity we observed 6-12 months postpartum is, therefore, unclear.

Similar to other studies, ${ }^{4,5}$ we did not observe any rebound relapses in RTX-treated women, even when treatment intervals exceeded 2 years. That extending RTX intervals beyond 1 year is effective was first described in the RTX relapsingremitting MS randomized controlled trial (RCT) where efficacy was sustained in most patients after $2,000 \mathrm{mg}$ induction. ${ }^{6}$ A recent RCT found that $77 \%$ of patients were still relapse-free 3 years after a single dose of $1,000 \mathrm{mg}$, followed by glatiramer acetate. ${ }^{5}$ What role an intervening pregnancy plays in the efficacy of extended dosing intervals we observed is unclear.

Findings from previous studies strongly suggested that every 6-month infusion of RTX at doses higher than those used in this study increases the risk of harm without added benefit in most patients. ${ }^{33-35}$ Safety advantages of using lower doses and longer dosing interval for RTX and other B-cell depleting agents are fewer infections and less hypogammaglobulinemia. ${ }^{23,24,34}$ Maternal hypogammaglobulinemia would be expected to increase the risk of neonatal and maternal infections because the placental transfer of maternal antibodies is a critical source of humoral immunity in neonates. B cells play a broader, yet unclear, role in maintaining or disrupting normal pregnancies. ${ }^{36}$ Recent advances in studies of regulatory B-cell populations indicate shifting dynamics during pregnancy. ${ }^{36}$ That this could affect repopulation of specific B-cell subsets after prepregnancy B-cell depletion seems plausible, but whether this would result in improved or worsened pregnancy outcomes remains murky. Future studies examining immunoglobulin levels, B-cell subset repopulation, and pregnancy and neonatal outcomes are needed.

We did not find any concerning safety signals. None of the women developed serious infections or chorioamnionitis. The rates of other pregnancy complications potentially signaling occult infections, including late miscarriages, stillbirths, or low birthweight, were comparable with, or lower than, the 
expected rates. Specifically, we observed $8.1 \%$ of pregnancies ending in preterm births and $7.9 \%$ low birthweight neonates with only $1(2.8 \%)$ low birthweight singleton. The expected national and California-specific rates are $10 \%$ and $8.8 \%$ for preterm births ${ }^{37}$ and $8.3 \%$ and $7.0 \%$ for low birthweight babies, ${ }^{38}$ respectively, and $6.6 \%$ for low birthweight singletons nationally. ${ }^{16}$ No major malformations ( $3 \%$ expected nationally $\left.^{39}\right)$, terminations because of congenital anomalies, or stillbirths $\left(1 \%\right.$ expected nationally $\left.{ }^{18}\right)$ were found. Two cases of stillbirths after B-cell depleting treatments in women with MS have been reported, 1 following $\mathrm{RTX}^{40}$ and another with ocrelizumab, ${ }^{41}$ but whether these women had other risk factors for adverse pregnancy outcomes and whether this exceeds the expected rates are unknown. The 2 significant adverse pregnancy outcomes, neonatal death and perinatal stroke, do not appear to be RTX related. Neonatal death is a known complication of extremely preterm twin pregnancies. Perinatal ischemic stroke occurs in 1 per 3,500 live births, and an idiopathic etiology is common. ${ }^{42}$ Future studies should continue to examine these potential risks.

RTX is our treatment of choice in women with active MS who are struggling with infertility because it is unclear if or when they will become pregnant. This is why the proportion of RTX-treated women with infertility in our study is relatively high. This is also the most likely explanation for why we observed a relatively high rate of miscarriages because infertility and miscarriages are comanifestations of subfertility. ${ }^{43}$ Thus, it is not surprising that we found that a history of infertility was more common in women with miscarriages than those without. We believe it is probably not related to RTX exposure because the characteristics of RTX use did not differ between pregnancies ending in miscarriages and those advancing to the third trimester and beyond. It is also reassuring that many women with miscarriages went on to have successful pregnancies despite continued RTX treatment. Nevertheless, given the possible role of regulatory B-cell subpopulations in implantation and maintenance of successful pregnancies, ${ }^{36}$ more studies are needed to accurately assess this potential risk.

The main limitation of this study is the relatively small sample size. We believe this is the most likely explanation for the lower than expected numbers of major malformations, stillbirths, preterm births, and low birthweight babies. The rates of pregnancy complications are particularly low when considering that a high proportion of women had at least 1 risk factor for adverse pregnancy outcomes. Alternatively, highquality prenatal care could explain these findings. Strengths of this study are a population-based sample with comprehensive medical records of the mother and infant, allowing unbiased and thorough assessment of maternal and infant outcomes and risk factors.

Although our findings are reassuring for women with suboptimally controlled MS who desire pregnancy, we caution against extending these findings to all women with MS or to treatment with ocrelizumab. Women diagnosed with MS today appear to have milder disease before, during, and after pregnancy compared with historical cohorts, and some are adequately controlled on glatiramer acetate, interferon-beta, or no treatment. ${ }^{1}$ Exposing these women to even a small increased risk of adverse pregnancy outcomes from routine RTX infusions likely outweighs any benefit they would experience. The risk of maternal and neonatal infections and ensuing adverse pregnancy outcomes could be higher with ocrelizumab compared with our findings. This is quite plausible because RTX is FDA-approved for rheumatoid arthritis (RA) without significant complications, but the ocrelizumab RA development program was ended because of the increased risk of serious infections. ${ }^{44}$ The FDA-approved MS ocrelizumab dose of $600 \mathrm{mg}$ every 6 months is substantially higher than those used in the RA development program. ${ }^{44}$

Taken together, our findings indicate that periconceptional RTX is a highly effective and safe treatment of women with suboptimally controlled MS or those on fingolimod or natalizumab. These women should start or switch to RTX before pregnancy, should be encouraged to breastfeed exclusively to maximize the general maternal and infant health benefits, and may not need to resume RTX until much later in the postpartum period. Future studies to determine the minimum RTX dosing interval are needed to optimize safety, particularly in young women who will want to get pregnant in the more distant future.

\section{Acknowledgment}

We thank Dr. Dean P. Sarco (Los Angeles Medical Center, Department of Neurology, Southern California Permanente Medical Group) for assistance reviewing the record of the infant with perinatal stroke.

\section{Study funding}

This study was supported in part by Patient-Centered Outcomes Research Institute (PCORI/MS-1511-33,196 PIs: Langer-Gould and Piehl).

\section{Disclosure}

J. Smith reports no disclosures relevant to the manuscript. $\mathrm{K}$. Hellwig has received speaker and research honoraria from Biogen Idec, Germany, Teva, Sanofi Genzyme, Novartis, Bayer Healthcare, Merck Serono, and Roche. K. Fink has received research grants from Biogen, served on advisory boards for Roche and Alexion, and has held a lecture for Biogen. D.J. Lyell serves as a consultant for Bloomlife Technology and an investor for Zenflow. F. Piehl has received research grants from Genzyme, Merck KGaA, and Novartis and fees for serving as Chair of DMC in clinical trials with Parexel. A. Langer-Gould has received grant support and awards from the National Institutes of Health, PatientCentered Outcomes Research Institute, and the National MS Society. She currently serves as a voting member on the California Technology Assessment Forum, a core program of the Institute for Clinical and Economic Review (ICER). She 
has received sponsored and reimbursed travel from ICER. Go to Neurology.org/NN for full disclosures.

\section{Publication history}

Received by Neurology: Neuroimmunology \& Neuroinflammation December 26, 2019. Accepted in final form March 24, 2020.

Appendix Authors

\begin{tabular}{lll}
\hline Name & Location & Contribution \\
\hline $\begin{array}{l}\text { Jessica B. } \\
\text { Smith, } \\
\text { MPH }\end{array}$ & $\begin{array}{l}\text { Department of Research \& } \\
\text { Evaluation, Kaiser } \\
\text { Permanente Southern } \\
\text { California, Pasadena, CA }\end{array}$ & $\begin{array}{l}\text { Collected, analyzed, } \\
\text { and interpreted the } \\
\text { data; revised the } \\
\text { manuscript for conten }\end{array}$ \\
$\begin{array}{l}\text { Kerstin } \\
\text { Hellwig, } \\
\text { MD }\end{array}$ & $\begin{array}{l}\text { Department of Neurology, } \\
\text { St. Josef Hospital, Bochum, }\end{array}$ & $\begin{array}{l}\text { Interpreted the data; } \\
\text { revised the manuscrip } \\
\text { formany }\end{array}$
\end{tabular}

\begin{tabular}{lll}
\hline $\begin{array}{l}\text { Katharina } \\
\text { Fink, MD, } \\
\text { PhD }\end{array}$ & $\begin{array}{l}\text { Department of Clinical } \\
\text { Neuroscience, Karolinska } \\
\text { Institutet and Center for } \\
\text { Neurology, Academic } \\
\text { Specialist Center, } \\
\text { Stockholm, Sweden }\end{array}$ & $\begin{array}{l}\text { Interpreted the data; } \\
\text { revised the manuscript } \\
\text { for content }\end{array}$ \\
\hline $\begin{array}{l}\text { Deirdre J. } \\
\text { Lyell, MD }\end{array}$ & $\begin{array}{l}\text { Department of Obstetrics } \\
\text { \& Gynecology - Maternal } \\
\text { Fetal Medicine, Stanford } \\
\text { University School of } \\
\text { Medicine, Palo Alto, CA, } \\
\text { USA }\end{array}$ & $\begin{array}{l}\text { Interpreted the data; } \\
\text { revised the manuscript } \\
\text { for content }\end{array}$ \\
\end{tabular}

Fredrik Department of Clinical

Piehl, MD, Neuroscience, Karolinska

PhD Institutet and Department

of Neurology, Karolinska

University Hospital,

Stockholm, Sweden

\begin{tabular}{ll}
\hline Annette & Los Angeles Medical \\
Langer- & Center, Department of \\
Gould, MD, & Neurology, Southern \\
PhD & California Permanente \\
& Medical Group, Los \\
& Angeles, CA, USA
\end{tabular}

Designed and
conceptualized the
study; collected,
analyzed, and
interpreted the data;
drafted and revised the
manuscript for
intellectual content;
had full access to all the
data and takes
responsibility for the
integrity of the data and
accuracy of the data
analysis

Interpreted the data; revised the manuscript for content

\section{References}

1. Langer-Gould A, Smith JB, Albers KB, et al. Pregnancy-related relapses and breastfeeding in a contemporary multiple sclerosis cohort. Neurology Epub 2020 April 13

2. Langer-Gould AM. Pregnancy and family planning in multiple sclerosis. Continuum (Minneap Minn) 2019;25:773-792.

3. Cartron G, Blasco H, Paintaud G, Watier H, Le Guellec C. Pharmacokinetics of rituximab and its clinical use: thought for the best use? Crit Rev Oncol Hematol 2007; $62: 43-52$.

4. Juto A, Fink K, Al Nimer F, Piehl F. Interrupting rituximab treatment in relapsing remitting multiple sclerosis; no evidence of rebound disease activity. Mult Scler Relat Disord 2019;37:101468.

5. Honce JM, Nair KV, Sillau S, et al. Rituximab vs placebo induction prior to glatiramer acetate monotherapy in multiple sclerosis. Neurology 2019;92:e723-e732.

6. Hauser SL, Waubant E, Arnold DL, et al. B-cell depletion with rituximab in relapsing remitting multiple sclerosis. N Engl J Med 2008;358:676-688.

7. Meinl I, Havla J, Hohlfeld R, Kumpfel T. Recurrence of disease activity during pregnancy after cessation of fingolimod in multiple sclerosis. Mult Scler 2018;24: 991-994.

8. Chakravarty EF, Murray ER, Kelman A, Farmer P. Pregnancy outcomes after maternal exposure to rituximab. Blood 2011;117:1499-1506.
9. Das G, Damotte V, Gelfand JM, et al. Rituximab before and during pregnancy: a systematic review, and a case series in MS and NMOSD. Neurol Neuroimmunol Neuroinflamm 2018;5:e453. 10.1212/NXI.0000000000000453.

10. Beaber BE, Chi MD, Brara SM, Zhang JL, Langer-Gould AM. Immunomodulatory agents and risk of postpartum multiple sclerosis relapses. Perm J 2014;18:9-13.

11. Thompson AJ, Banwell BL, Barkhof F, et al. Diagnosis of multiple sclerosis: 2017 revisions of the McDonald criteria. Lancet Neurol 2018;17:162-173.

12. Langer-Gould A, Brara SM, Beaber BE, Zhang JL. The incidence of clinically isolated syndrome in a multi-ethnic cohort. J Neurol 2014;261:1349-1355.

13. Okuda DT. Radiologically isolated syndrome: MR imaging features suggestive of multiple sclerosis prior to first symptom onset. Neuroimaging Clin N Am 2017;27: 267-275.

14. Koebnick C, Langer Gould A, Gould MK, et al. Do the sociodemographic characteristics of members of a large, integrated health care system represent the population of interest? Permanente J 2012;16:37-41.

15. Metwally M, Ong KJ, Ledger WL, Li TC. Does high body mass index increase the risk of miscarriage after spontaneous and assisted conception? A meta-analysis of the evidence. Fertil Steril 2008;90:714-726.

16. Martin JA, Hamilton BE, Osterman MJ, Driscoll AK, Drake P. Births: Final Data for 2018. Natl Vital Stat Rep 2019;68:8.

17. Physical status: the use and interpretation of anthropometry. Report of a WHO Expert Committee. World Health Organ Tech Rep Ser 1995;854:1-452.

18. Centers for Disease Control and Prevention. What is Stillbirth? [online]. Available at: www.cdc.gov/ncbddd/stillbirth/facts.html. Accessed November 26, 2019.

19. Centers for Disease Control and Prevention. Preterm Birth [online]. Available at: www.cdc.gov/reproductivehealth/maternalinfanthealth/pretermbirth.htm. Accessed November 26, 2019.

20. Confavreux C, Hutchinson M, Hours MM, Cortinovis-Tourniaire P, Moreau T. Rate of pregnancy-related relapse in multiple sclerosis. Pregnancy in Multiple Sclerosis Group. N Engl J Med 1998;339:285-291.

21. Hellwig K, Rockhoff M, Herbstritt S, et al. Exclusive breastfeeding and the effect on postpartum multiple sclerosis relapses. JAMA Neurol 2015;72:1132-1138.

22. Greenland S, Pearce N. Statistical foundations for model-based adjustments. Annu Rev Public Health 2015;36:89-108.

23. Derfuss T, Weber MS, Hughes R, et al. Serum immunoglobulin levels and risk of serious infections in the pivotal Phase III trials of ocrelizumab in multiple sclerosis and their open-label extensions. Abstract presented at the ECTRIMS 2019 Congress; September 11-13; Stockholm, Sweden. ECTRIMS Online Library 2019.

24. Hallberg S, Boremalm M, Evertsson B, et al. Risk of hypogammaglobulinemia in longterm treatment with rituximab in multiple sclerosis. Abstract presented at the ECTRIMS 2019 Congress; September 11-13; Stockholm, Sweden. ECTRIMS Online Library 2019.

25. Langer-Gould A, Popat RA, Huang SM, et al. Clinical anddemographic predictors of long-term disability in patients with relapsing-remitting multiple sclerosis: a systematic review. Arch Neurol 2006;63:1686-1691.

26. Portaccio E, Ghezzi A, Hakiki B, et al. Postpartum relapses increase the risk of disability progression in multiple sclerosis: the role of disease modifying drugs. J Neurol Neurosurg Psychiatry 2014;85:845-850.

27. Vukusic S, Hutchinson M, Hours M, et al. Pregnancy and multiple sclerosis (the PRIMS study): clinical predictors of post-partum relapse. Brain 2004;127: 1353-1360.

28. Hughes SE, Spelman T, Gray OM, et al. Predictors and dynamics of postpartum relapses in women with multiple sclerosis. Mult Scler 2014;20:739-746.

29. Haghikia A, Langer-Gould A, Rellensmann G, et al. Natalizumab use during the third trimester of pregnancy. JAMA Neurol 2014;71:891-895.

30. Novi G, Ghezzi A, Pizzorno M, et al. Dramatic rebounds of MS during pregnancy following fingolimod withdrawal. Neurol Neuroimmunol Neuroinflamm 2017;4: e377. 10.1212/NXI.0000000000000377.

31. Portaccio E, Moiola L, Martinelli V, et al. Pregnancy decision-making in women with multiple sclerosis treated with natalizumab: II: maternal risks. Neurology 2018;90: e832-e839.

32. Victora CG, Bahl R, Barros AJ, et al. Breastfeeding in the 21st century: epidemiology, mechanisms, and lifelong effect. Lancet 2016;387:475-490.

33. Dunn N, Juto A, Ryner M, et al. Rituximab in multiple sclerosis: frequency and clinical relevance of anti-drug antibodies. Mult Scler 2018;24:1224-1233.

34. Emery P, Fleischmann R, Filipowicz-Sosnowska A, et al. The efficacy and safety of rituximab in patients with active rheumatoid arthritis despite methotrexate treatment: results of a phase IIB randomized, double-blind, placebo-controlled, dose-ranging trial. Arthritis Rheum 2006;54:1390-1400.

35. Salzer J, Svenningsson R, Alping P, et al. Rituximab in multiple sclerosis: a retrospective observational study on safety and efficacy. Neurology 2016;87:2074-2081.

36. Esteve-Sole A, Luo Y, Vlagea A, et al. B regulatory cells: players in pregnancy and early life. Int J Mol Sci 2018;19:E2099.

37. Martin JA, Hamilton BE, Osterman MJ, Driscoll AK, Drake P. Births: final data for 2018. Table I-19. Preterm births by race and Hispanic origin of mother: United States, each state and territory, 2018. Natl Vital Stat Rep 2019;68. Available at: www.cdc.gov/ nchs/data/nvsr/nvsr68/nvsr68_13 tables-508.pdf. Hyattsville, MD: National Center for Health Statistics.

38. Martin JA, Hamilton BE, Osterman MJ, Driscoll AK, Drake P. Births: final data for 2018. Table I-21. Low birthweight births, by race and Hispanic origin of mother: United States, each state and territory, 2018. Natl Vital Stat Rep 2019;68. Available at: www.cdc.gov/nchs/data/nvsr/nvsr68/nvsr68_13_tables-508.pdf. Hyattsville, MD: National Center for Health Statistics. 
39. Centers for Disease Control and Prevention. Data \& Statistics on Birth Defects [online]. Available at: www.cdc.gov/ncbddd/birthdefects/data.html. Accessed December 12, 2019.

40. Fink K, Gorczyca A, Smith JB, Piehl F, Langer-Gould A. Rituximab, multiple sclerosis and pregnancy. Poster presented at the ECTRIMS 2019 Congress; September 11-13; Stockholm, Sweden. ECTRIMS Online Library 2019.

41. Wray S, Kappos L, Vukusic S, et al. An Update on Pregnancy Outcomes Following Ocrelizumab Treatment in Patients with Multiple Sclerosis and Other Autoimmune
Diseases. Poster presented at the 2018 Annual Meeting of the Consortium of Multiple Sclerosis Centers (CMSC); May 30-June 2; Nashville, TN. 2018.

42. Agrawal N, Johnston SC, Wu YW, Sidney S, Fullerton HJ. Imaging data reveal a higher pediatric stroke incidence than prior US estimates. Stroke 2009;40:3415-3421.

43. Agenor A, Bhattacharya S. Infertility and miscarriage: common pathways in manifestation and management. Womens Health (Lond) 2015;11:527-541.

44. Emery P, Rigby W, Tak PP, et al. Safety with ocrelizumab in rheumatoid arthritis: results from the ocrelizumab phase III program. PLoS One 2014;9:e87379. 


\section{Neurology \\ Neuroimmunology \& Neuroinflammation}

Rituximab, MS, and pregnancy

Jessica B. Smith, Kerstin Hellwig, Katharina Fink, et al.

Neurol Neuroimmunol Neuroinflamm 2020;7;

DOI 10.1212/NXI.0000000000000734

This information is current as of May 1, 2020

\section{Updated Information \& Services}

References

Citations

Subspecialty Collections

Permissions \& Licensing

Reprints including high resolution figures, can be found at:

http://nn.neurology.org/content/7/4/e734.full.html

This article cites 34 articles, 5 of which you can access for free at: http://nn.neurology.org/content/7/4/e734.full.html\#\#ref-list-1

This article has been cited by 6 HighWire-hosted articles: http://nn.neurology.org/content/7/4/e734.full.html\#\#otherarticles

This article, along with others on similar topics, appears in the following collection(s):

Multiple sclerosis

http://nn.neurology.org//cgi/collection/multiple_sclerosis

Information about reproducing this article in parts (figures,tables) or in its entirety can be found online at:

http://nn.neurology.org/misc/about.xhtml\#permissions

Information about ordering reprints can be found online: http://nn.neurology.org/misc/addir.xhtml\#reprintsus

Neurol Neuroimmunol Neuroinflamm is an official journal of the American Academy of Neurology.

Published since April 2014, it is an open-access, online-only, continuous publication journal. Copyright

Copyright (C) 2020 The Author(s). Published by Wolters Kluwer Health, Inc. on behalf of the American

Academy of Neurology.. All rights reserved. Online ISSN: 2332-7812.

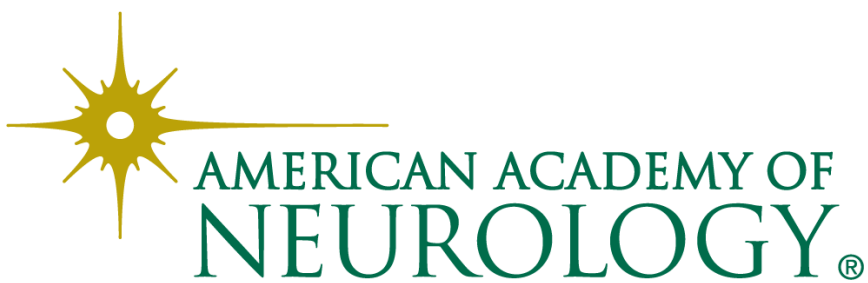

